\title{
NOTAS TAXONÔMICAS E ESPÉCIES NOVAS DE NANANTHIDIUM MOURE E DESCRIÇÃO DO MACHO DE BOTHRANTHIDIUM MOURE (HYMENOPTERA, MEGACHILIDAE) ${ }^{1}$
}

\section{Danúncia Urban ${ }^{2}$}

\begin{abstract}
TAXoNomic NOTES AND NEW SPECIES OF NANANTHIDIUM MOURE AND DESCRIPTION OF THE MALE OF Bothranthidium Moure (Hymenoptera, Megachilidae). The Anthidiine bees Nananthidium analuizae sp.n., Nananthidium foersteri sp.n. and Nananthidium panamense sp.n. are described. New combinations are proposed to Nananthidium quadrimaculatum (Cockerell, 1927) and Nananthidium gualanense (Cockerell, 1912). By the first time notes on the morphology of the male of Bothranthidium Moure, 1947 are presented.

KEY WORDS. Apoidea, Megachilidae, Anthidinae, Nananthidium, Bothranthidium, taxonomy
\end{abstract}

Nananthidium foi proposto por Moure (1947) para duas espécies de Dianthidiini, N. bettyae Moure, 1947 de São Paulo, Brasil e N. willineri Moure, 1947 de San Estanislao, Paraguai. Uma terceira espécie, Nananthidium tamaulipanus, do México, foi descrita por MICHENER \& ORDWAY (1964). GRISWOLD \& MICHENER (1988) colocaram Nananthidium como sub-gênero de Anthodioctes Holmberg, 1903 e incluíram Dianthidium gualanense Cockerell, 1912, da Guatemala, entre as espécies do gênero. URBAN (1992) citou Nananthidium banski (Cockerell, 1928), do Panamá.

A identificação de exemplares da Coleção de Entomologia Pe. J.S. Moure, Curitiba, Departamento de Zoologia, Universidade Federal do Paraná (DZUP) e do Snow Entomological Museum, Lawrence, University of Kansas (SEMK), levou ao reconhecimento e à descrição de três espécies novas e à elaboração de uma chave para a identificação das espécies com a distribuição geográfica do material examinado. Não foi incluído na chave $N$. banksi, por não ter sido examinado o tipo. As medidas dadas nas descrições das espécies são em milímetros.

\section{Descrições}

\section{Nananthidium analuizae sp.n.}

Figs 1, 2, 4

Diagnose. Colorido predominante amarelo na cabeça; fêmea com os tergos amarelo-ocráceos com faixas amarelas e o macho com grande área amarelo-ocrácea nos mesepisternos e metepisternos.

1) Contribuição número 1015 do Departamento de Zoologia, Universidade Federal do Paraná.

2) Departamento de Zoologia, Universidade Federal do Paraná. Caixa Postal 19020, 81531-990 Curitiba, Paraná, Brasil. Bolsista do CNPq. 
Holótipo fêmea. Tegumento preto nas mandíbulas, parte das genas e da fronte; amarelo no clípeo e nas áreas paroculares, nestas quase até a tangente ocelar inferior e arredondado dorsalmente; grande nódoa supraclipeal amarelo-ocrácea, estreitada junto à parte inferior das carenas interalveolares e alargando na fronte onde se divide em dois ramos que acompanham as carenas; larga faixa amarela pós-ocelar, prolongada atrás dos olhos até a carena pré-occipital, estreitando na metade ventral das genas. Antenas amarelo-ferrugíneas, mais amareladas no escapo, pedicelo e nos dois flagelômeros basais. Mesosoma preto com as seguintes áreas amarelas: estrias laterais no mesoscuto prolongadas anteriormente em faixas látero-basais, lobos e cantos posteriores do pronoto, escutelo e axilas; metanoto amarelo-méleo; grande nódoa dorsal amarela nos mesepisternos, com mescla de acastanhado; nódoa amarela dorsal nos metepisternos; amarelo-acastanhado na base das asas e nas tégulas e em parte das pernas; restante das asas castanho, pernas com as coxas enegrecidas e os trocanteres castanhos. Tergos e esternos de um amarelo levemente acastanhado, com margem translúcida larga amarelo-mélea; primeiro e segundo tergos com grandes nódoas amarelas laterais unidas por faixa estreita um pouco mais pálida que o tegumento de fundo, no primeiro as nódoas arredondadas e no segundo formando faixas laterais quase alcançando a base do tergo; faixa amarela do terceiro ao quinto tergo, muito larga no quarto e quinto; tergo distal quase todo amarelo, com margem castanha.

Comprimento aproximado 5,33; comprimento da asa anterior a partir do esclerito costal 4,33; largura da cabeça 1,88; comprimento do olho 1,40; distância interorbital superior $1,24 \mathrm{e}$ a inferior 0,92 .

Alótipo macho. Tegumento amarelo em grande parte da cabeça, com área preta confinada ao vértice e parte dorsal da fronte, o amarelo da parte ventral da fronte projetado dorsalmente de forma bilobada, com profundo recorte mediano e incluindo as carenas interalveolares; mandíbulas com ápice preto; escapo amarelo ventralmente, restante da antena amarelo-ocráceo; mesosoma preto com grandes nódoas amarelas; pronoto preto no disco, dorsalmente, e amarelo nas demais áreas; mesoscuto com duas largas nódoas em J invertido, avançando um pouco para o disco na base; axilas amarelas; metanoto amarelo com área basal preta; tégulas amareloacastanhadas; amarelo na metade dorsal dos mesepisternos, grande parte dos metepisternos e parte do propódeo; pernas amarelo-acastanhadas. Do primeiro ao quinto tergo com faixa amarela discal, no primeiro a área basal amarelo-acastanhada e a faixa amarela muito larga; no segundo a faixa mais estreita no meio e com mescla de castanho; no sexto tergo a faixa amarela mais escurecida; sétimo castanho; três esternos basais amarelos, nos seguintes a pilosidade encobrindo o tegumento.

Comprimento aproximado 5,42; comprimento da asa anterior a partir do esclerito costal 4,50; largura da cabeça 1,92; comprimento do olho 1,30; distância interorbital superior $1,16 \mathrm{e}$ a inferior 0,84 .

Distribuição geográfica. Venezuela, Zulia; ColômBIA, Boyaca.

Holótipo fêmea. ColômBIA, Boyaca, Muzo, 900m, VII.1936, J. Bequaert leg. (DZUP). Alótipo da VeNEZUELA, Zulia, Maracaibo, 16.IX.1973, R. M. Bohart leg. (SEMK). 
Comentários. A fêmea de Nananthidium willineri, aproxima-se desta espécie pelas grandes áreas amarelo-ferrugíneas da cabeça, difere pelos tergos pretos com faixas amarelas estreitas; o macho de $N$. willineri não tem faixa amarela completa no tergo basal e os mesepisternos e metepisternos são pretos.

Etimologia. Em homenagem à Bióloga Ana Luiza Mattana.
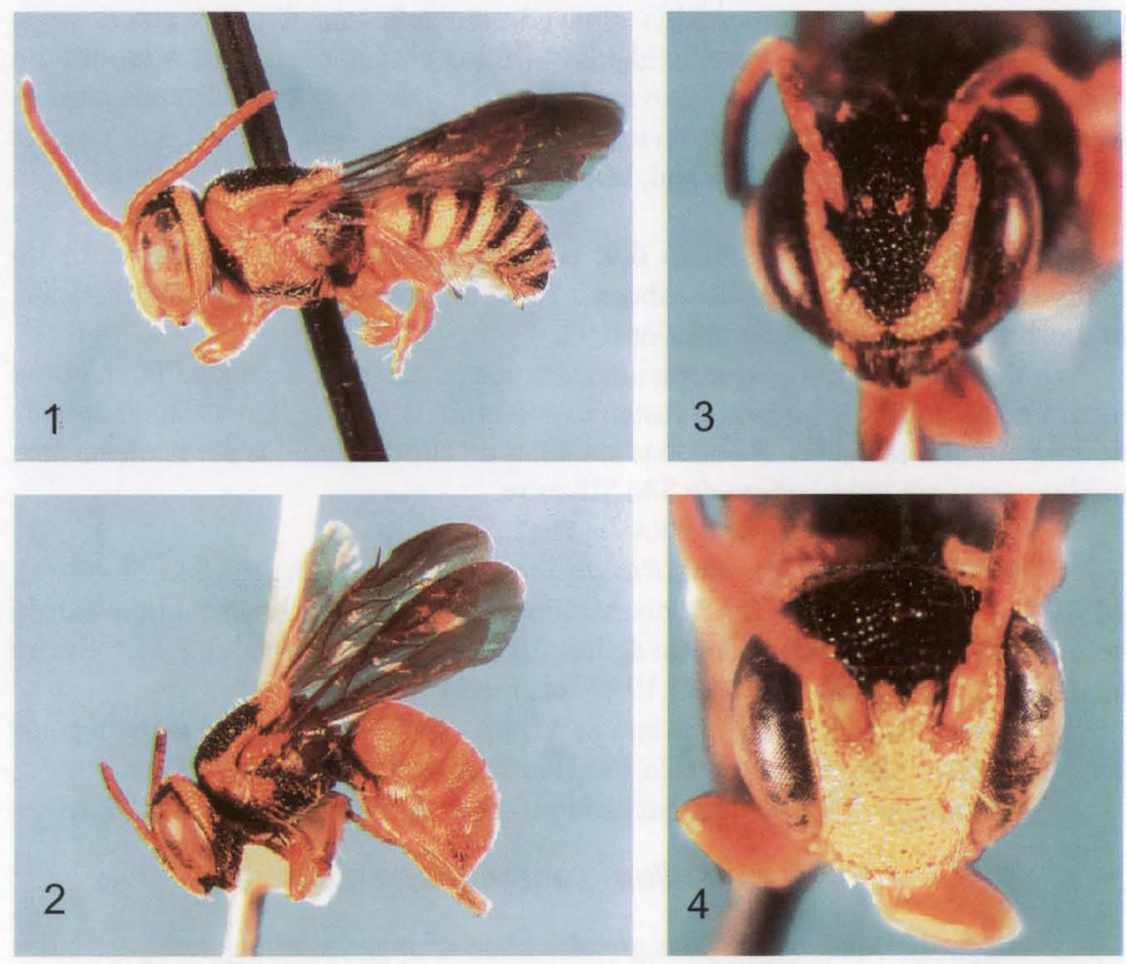

Figs 1-4. (1-2) Nananthidium analuizae. (1) fêmea de perfil; (2) macho de perfil; (3) Nananthidium foersteri, cabeça do macho em vista frontal; (4) Nananthidium analuizae, cabeça do macho em vista frontal.

\section{Nananthidium foersteri sp.n.}

Fig. 3

Diagnose. O macho é facilmente reconhecido pelas grandes nódoas amarelas triangulares nos lados do clípeo e pelas faixas amarelas estreitas dos tergos, escapo amarelo-ferrugíneo.

Holótipo macho. Tegumento predominante preto, com as seguintes áreas amarelas: nódoa na base das mandíbulas; duas grandes manchas laterais triangulares no clípeo; paroculares inferiores, o amarelo contornando a sutura subantenal e terminando abaixo da tangente ocelar inferior; duas pequenas nódoas interalveolares; estria pós-ocelar de um amarelo-ocráceo, ultrapassando um pouco a parte dorsal dos olhos e levemente interrompida no meio; antenas castanhas, com amarelo 
ferrugíneo no escapo, pedicelo e flagelômero basal. Pronoto com pequenas nódoas amarelas nos lobos; mesoscuto com faixas amarelas látero-basais estreitas alongadas nos flancos até um terço do seu comprimento; tégulas e base das asas amareloacastanhadas, restante das asas tingido com castanho; escutelo com duas manchas laterais amarelas, axilas com nódoa arredondada tambem amarela; pernas com os artículos basais enegrecidos, nas posteriores o enegrecido até a tíbia, no restante amarelo-acastanhadas, com nódoa alongada amarela nos fêmures anteriores e medianos, a nódoa menor nos medianos. Tergos castanho-escuros, o basal com grandes nódoas laterais amarelas ovaladas, no segundo com faixas laterais arqueadas amarelas, afastadas da base; do terceiro ao sexto tergo com faixa discal amarela estreita, no sexto a faixa mais distal; sétimo tergo castanho; esternos castanhos com áreas amarelo-acastanhadas.

Comprimento aproximado 6,0; comprimento da asa anterior a partir do esclerito costal 4,67; largura da cabeça 2,32; comprimento do olho 1,44; distância interorbital superior $1,30 \mathrm{e}$ a inferior 0,92 .

Variações. Estria pós-ocelar interrompida ou não no meio; mandíbulas quase inteiramente amarelas ou com o castanho predominando; tégulas castanhas em vez de amarelo-acastanhadas. As nódoas amarelas do clípeo fundidas por pequena área médio-apical em um parátipo de São Silvestre.

Distribuição geográfica. BRASIL, Rio de Janeiro.

Holótipo macho. Brasil, Rio de Janeiro: Rio de Janeiro (São Silvestre), 4.IV.1960, M. Alvarenga leg.; dois parátipos machos com a mesma etiqueta do holótipo. Parátipos, machos, do Rio de Janeiro, (Represa Rio Grande), F.M. Oliveira leg., 30.X.1964 um macho, 10.XI.1966 dois machos (DZUP).

Comentários. Espécie próxima de $N$. panamense sp.n., porém distinta pelos caracteres diagnósticos e conhecida somente do sudeste brasileiro.

Etimologia. Espécie dedicada ao Prof. Luís Amilton Foerster, DZUP.

\section{Nananthidium panamense sp.n.}

Diagnose. Macho com duas grandes nódoas amarelas triangulares nos lados do clípeo como em Nananthidium foersteri sp.n., distingue-se pelas faixas amarelas largas dos tergos e pelo escutelo quase inteiramente amarelo, escapo enegrecido dorsalmente.

Holótipo macho. Tegumento preto. Mandíbulas pretas, clípeo com duas grandes nódoas amarelas laterais até as fóveas tentoriais, as nódoas unidas por uma área muito estreita apical; paroculares amarelas, a nódoa contornando a sutura subantenal quase até o alvéolo, diminuindo progressivamente e terminando abaixo da tangente ocelar; duas nódoas interalveolares amarelas curtas e estreitas; estria pós-ocelar amarela contínua, até o terço dorsal das genas; antenas ferrugíneas ventralmente, no lado dorsal enegrecidas incluindo o escapo. Pronoto com nódoa discal amarela nos lobos; mesoscuto com faixas látero-basais amarelas; quase todo o escutelo amarelo, com preto somente na área basal deprimida; axilas amarelas; pernas anteriores com parte do fêmur, tíbia e tarso ferrugíneos, o fêmur com estria amarela; as medianas com estria amarela no fêmur e a tíbia ferrugínea na face anterior; as pernas posteriores enegrecidas incluindo os tarsômeros distais; tégulas

Revta bras. Zool. 15 (3): 621 - 632, 1998 
castanho-escuras. Asa tingidas com enegrecido desde a base. Dois tergos basais com nódoas amarelas laterais grandes, arredondadas no primeiro e em forma de faixas no segundo; do terceiro ao quinto com faixa amarela discal, tão larga como o dobro do diâmetro do ocelo no terceiro tergo, um pouco mais estreita nos dois seguintes, as faixas estreitando suavemente nos flancos; sexto tergo com faixa amarela subapical.

Comprimento aproximado 6,33; comprimento da asa anterior a partir do esclerito costal 4,92; largura da cabeça 2,16; comprimento do olho 1,56; distância interorbital superior 1,48 e a inferior 0,96 .

Distribuição geográfica. PANAMÁ, Darién.

Holótipo macho. Panamá, Darién: 6.VI.1996, Ashe \& Brooks leg. (SEMK).

Comentário. Uma fêmea de Nananthidium, de Barro Colorado, PANAMÁ, foi descrita como Dianthidium banksi Cockerell, 1928; o autor da espécie comparou-a com outra espécie que descreveu da Bolívia em 1927, Dianthidium quadrimaculatum (Cockerell, 1927) também um Nananthidium. Esta fêmea não foi vista e o macho da espécie permanece desconhecido. É possível que o macho descrito como $N$.panamense seja o macho de $N$. banksi, mas isto só será resolvido com o estudo de exemplares deste gênero coletados nessa região.

Etimologia. Nome alusivo ao país de origem do exemplar.

\section{Notas taxonômicas}

\section{Nananthidium gualanense (Cockerell, 1912) comb.n.}

\section{Figs 5,7}

Dianthidium gualanense Cockerell, 1912, Ann. Mag. Nat. Hist. 9 (8): 560.

Anthodioctes (Nananthidium) gualanense; Griswold \& Michener, 1988, Journ. Kansas Ent. Soc. 61 (1): 30 .

O holótipo macho, de Gualán, Guatemala, cedido para estudo pelo American Museum of Natural History, tem o clípeo e as paroculares inferiores amarelos, nas paroculares o amarelo terminando em estria fina abaixo dos ocelos; estrias pós-ocelares amarelas curtas, dos ocelos laterais até pouco além do topo dos olhos; mesosoma preto, incluindo o mesoscuto; escutelo e axilas com margem obscura castanha; os dois tergos basais com nódoas amarelas laterais; o terceiro com faixa amarela estreita; no quarto a faixa amarela com o dobro da largura do anterior, quinto e sexto tergos quase inteiramente amarelos, o distal com amarelo na base.

Variações. Dos exemplares coletados no MÉXICO, foram vistos: sete fêmeas de Jalisco com cabeça e mesosoma pretos, uma fêmea com mancha amarela irregular nas paroculares inferiores e fina orla amarela no escutelo; uma fêmea com duas nódoas basais amarelas grandes no sexto tergo, nas demais predomina o amarelo no sexto tergo; duas fêmeas de Guerrero com faixa apical obsoleta castanha no escutelo, um macho com todo o vértice e o mesosoma pretos; um macho e três fêmeas de Oaxaca, El Camaron com todo o vértice preto, as fềmeas com a cabeça e o mesosoma pretos; uma fêmea com estrias obsoletas castanho-amareladas nas paroculares e a margem do escutelo amarela no meio passando para castanha nos lados. 
Um macho de HondURAS, Tegucigalpa, com estrias pós-ocelares amarelas quase unidas no meio e ultrapassando o topo dos olhos, nódoas laterais amareloferrugíneas na base do mesoscuto, margem do escutelo e das axilas amarelos, no escutelo com interrupção mediana. Fêmeas de CosTA RiCA, Guanacaste, com estrias pós-ocelares amarelas pouco distintas, paroculares com estrias amarelas filiformes ou um pouco alargadas inferiormente; pequenas áreas amarelo-méleas na base do mesoscuto; uma com o mesoscuto e escutelo pretos, as demais com o escutelo orlado posteriormente com amarelo, e uma com pequenas nódoas amarelas látero-apicais no clípeo.

Distribuição geográfica. MÉXICO, Oaxaca, Jalisco, Guerrero; GuATEMALA, Gualán; HoNDURAS, Tegucigalpa; CosTA RiCA, Guanacaste.

\section{Nananthidium quadrimaculatum (Cockerell, 1927) comb.n.}

Fig. 6

Dianthidium quadrimaculatum Cockerell, 1927, Proc. U.S. Nat. Mus. 71 (12): 8. Anthodioctes quadrimaculatum; Michener, 1948, Amer. Mus. Novit. 1381: 20.

Um síntipo fêmea, de Beni, Bolívia, foi examinado por J.S. Moure que observou tratar-se de um Nananthidium. Está depositado no National Museum of Natural History. Foram vistos machos e fêmeas das localidades relacionadas abaixo.

Distribuição geográfica. Peru: Huánuco, Tingo Maria; Bolívia, Beni: Huachi; La Paz: Tumupasa. ARgentinA, Salta: Pocitos. BRASIL, Acre: Iquiri.

\section{Nananthidium willineri Moure, 1947}

Fig. 8

Nananthidium willineri Moure, 1947, Publ. Avuls. Mus. Paranaense 3: 29.

MOURE (1947) descreveu a fêmea tendo em mãos três exemplares do PARAGUAI, diferentes quanto à extensão das nódoas ferrugíneas na cabeça. Holótipo com as nódoas laterais do clípeo e as interalveolares ferrugíneo-escuras; estrias paroculares ferrugíneo-amareladas e a pós-ocelar ferrugínea; um parátipo com as nódoas do clípeo amarelo-ferrugíneas e as paroculares amarelo-cromo; outro parátipo com o clípeo quase todo ferrugíneo, mancha na supraclipeal e parte da fronte, genas e lados do clípeo amarelo-ferrugíneos. MICHENER \& ORDWAY (1964) comentaram que as diferenças na estrutura e pontuação entre $N$. bettyae e $N$. willineri desapareciam quando examinadas grandes séries e que $N$. willineri poderia ser uma subespécie de $N$. bettyae. Consideramos válidas as duas espécies.

Foi constatada notável variação no colorido das fêmeas. Nos exemplares coletados em Pocitos, Salta e Jujuy, Argentina, além de fêmeas semelhantes ao holótipo, foram vistos espécimens com grande parte das genas e quase toda a face ferrugíneas; de Santa Cruz, Bolívia e Cáceres, Mato Grosso, Brasil, com toda a cabeça ferrugínea, como também as nódoas em $\mathrm{J}$ invertido do mesoscuto; escutelo ferrugíneo com área amarelada. Exemplares da Bahia, Espírito Santo, Minas Gerais e Mato Grosso, com nódoas amarelas em vez de ferrugíneas na cabeça e mesosoma, a estria pós-ocelar amarela bem delimitada e estreita; de Itapina, Espírito Santo, foram vistas fêmeas com o escutelo quase todo amarelo; nódoas amarelas do mesoscuto em forma de $\mathrm{J}$ invertido com o ramo lateral até o ápice e bem estreito, e 
a estria amarela pós-ocelar invadindo os dois terços dorsais das genas; de Vitória da Conquista, Bahia, duas fêmeas com duas grandes nódoas amarelas triangulares no clípeo; uma com o clípeo castanho-pálido na metade apical, entre as nódoas amarelas, três com faixa amarela na metade apical do clípeo, trilobulada em direção à sutura epistomal, os lóbulos separados por estrias pretas irregulares; este mesmo desenho amarelo foi observado no clípeo de uma fêmea coletada em Pedra Azul, Minas Gerais e uma de Cáceres; outro exemplar de Cáceres com o clípeo em grande parte amarelo.
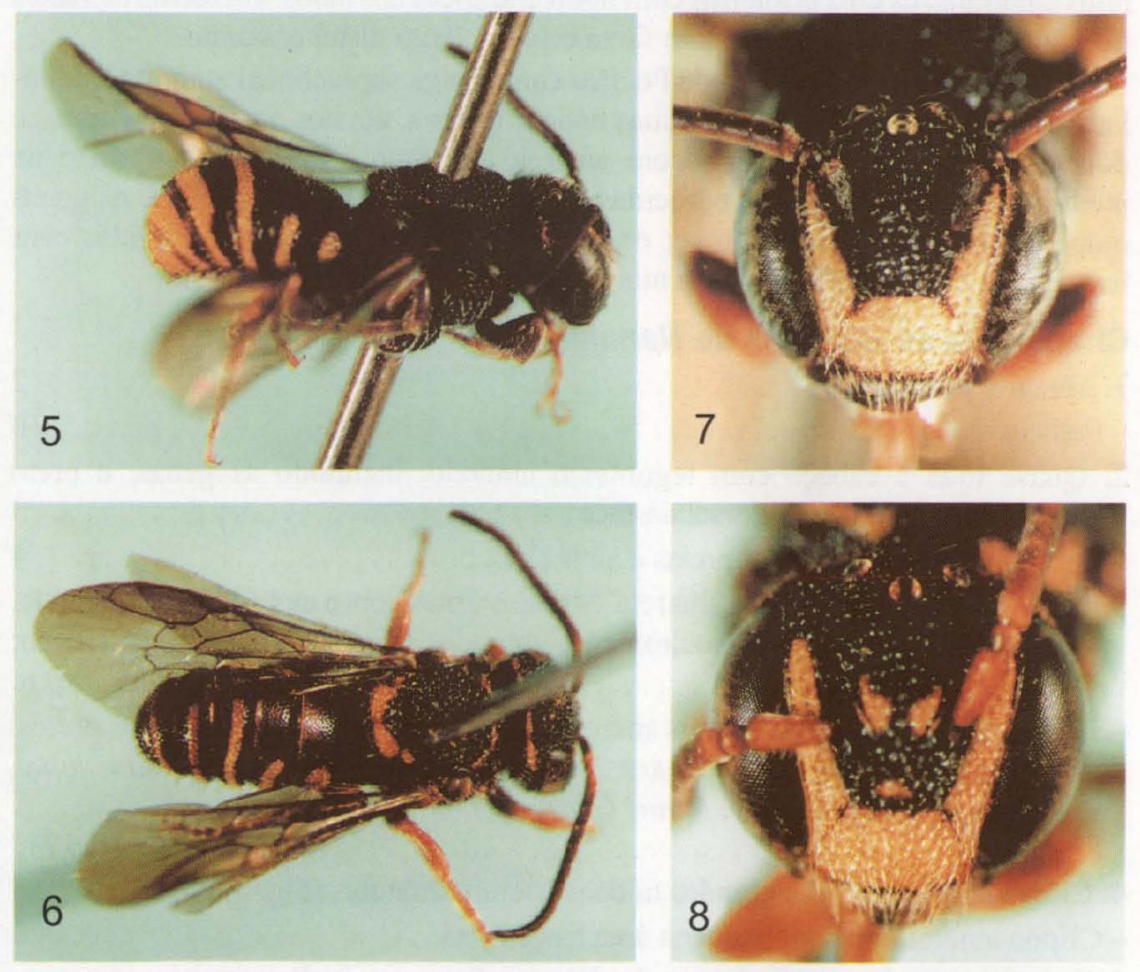

Figs 5-8. (5) Nananthidium gualanense holótipo macho, de perfil; (6) Nananthidium quadrimaculatum vista dorsal do macho; (7) Nananthidium gualanense vista frontal da cabeça do holótipo; (8) Nananthidium willineri cabeça do macho em vista frontal.

O macho, anteriormente desconhecido, é descrito a seguir, com as variações constatadas no material examinado. Tegumento preto, com as seguintes áreas amarelas: clípeo, grande nódoa na metade basal das mandíbulas; paroculares inferiores amarelas, o amarelo estreitando aos poucos dorsalmente e terminando a meia distância entre os alvéolos antenais e o ocelo mediano; nódoa ou faixa na área supraclipeal; estrias interalveolares; estria pós-ocelar, prolongada no terço dorsal das genas. Todo o lado ventral das antenas e os três artículos basais amarelo-ferru- 
gíneos, lado dorsal castanho do segundo flagelômero ao distal. Lobos pronotais com nódoa amarela pequena; mesoscuto com faixas látero-basais amarelas, prolongadas nos lados até o meio, e passando a castanho-amareladas distalmente; escutelo com duas grandes nódoas amarelas, axilas amarelas na metade posterior; pernas com os artículos basais castanhos, nas anteriores a coxa e o trocanter, nas medianas até o fêmur e nas posteriores incluindo a tíbia, restante amarelo-ocráceo com estria amarelada na tíbia e fềmur anteriores e nódoa amarela no ápice do fêmur mediano; tarsômeros posteriores castanhos. Asas castanhas desde a base. Tergos com desenhos amarelos, os dois primeiros com nódoas grandes aos lados, em forma de faixas no segundo; terceiro ao sexto com faixa estreita, tergo distal castanho.

Variações. Exemplares de Pocitos com a faixa supraclipeal amarela trilobulada dorsalmente ou dividida em duas nódoas laterais, um dos machos de Pocitos e dois de Santa Cruz, BolíviA, com amarelo em toda a área supraclipeal e na interalveolar, com as estrias paroculares amarelas unidas à pós-ocelar e as genas quase inteiramente amarelo-ocre; os de Santa Cruz com as genas tingidas com ferrugíneo. Os tergos distais com maior ou menor extensão do amarelo.

\section{Chave para as espécies de Nananthidium}

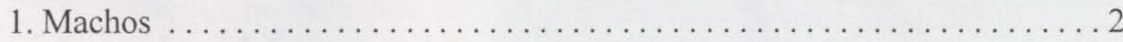

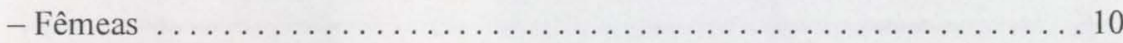

2. Quase toda a cabeça com tegumento amarelo, incluindo as genas, o preto confinado ao terço dorsal da face ........................ 3

- Cabeça com grandes áreas pretas e amarelas ..................... 4

3. Tergo basal com larga faixa amarela. Mesepisternos com a metade dorsal amarela. Metepisternos quase inteiramente amarelos (Fig. 1). VenEzUELA: Zulia; COLÔMBIA: Boyaca ....................... analuizae sp.n.

- Tergo basal com nódoas laterais amarelas. Mesepisternos e metepisternos pretos. Bolívia, Santa Cruz; Paraguai: San Stanislao; Argentina: Salta, Jujuy; BRASIL: Mato Grosso, Minas Gerais, Bahia, Espirito Santo ............ willineri Moure, 1947

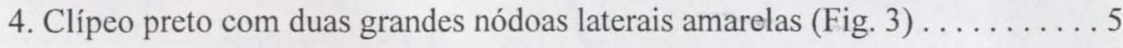
- Clípeo amarelo ou com pequena área basal preta ................. 6

5. Escutelo com duas nódoas amarelas laterais. Faixas amarelas estreitas nos tergos (igualando um diâmetro de ocelo). Mandíbulas com nódoa amarela. Escapo ferrugíneo. BRAsIL: Rio de Janeiro . . . . . . . . . . . . . . foersteri sp.n.

- Escutelo amarelo, com estreita base preta. Tergos com faixas amarelas largas, igualando dois diâmetros de ocelo. Mandíbulas pretas. Escapo preto dorsalmente. PANAMÁ ..................... panamense $\mathbf{s p . n .}$

6. Área supraclipeal com nódoa amarela junto à sutura epistomal ou inteiramente amarela. Duas nódoas interalveolares amarelas alongadas (Fig. 8) ....... ........................................ willineri

- Área supraclipeal preta. Espaço interalveolar sem nódoas amarelas . . . . . . . . 7

7. Com faixa amarela larga do terceiro ao sexto tergo, no terceiro igualando dois diâmetros de ocelo, e do quarto ao sexto o amarelo em quase todo o tergo 
(Fig. 5); sétimo tergo amarelo na metade basal. Antenas com escapo preto (Fig. 7). MÉxICO: Oaxaca, Jalisco, Guerrero; CostA RICA: Guanacaste; Honduras: Tegucigalpa ............... gualanense (Cockerell, 1912)

- Com faixa amarela estreita do terceiro ao sexto tergo, a faixa igual ou um pouco mais larga que um diâmetro de ocelo; sétimo tergo enegrecido ou ferrugíneo em parte. Antenas com escapo variável . . . . . . . . . . . . . 8

8. Escapo, pedicelo e flagelômero basal inteiramente amarelo-ferrugíneos, sem área castanho-escura. Tégulas amarelo-acastanhadas. PARAgUAI, Caaguazú; Brasil: Espírito Santo, São Paulo, Paraná . . . . . . . . bettyae Moure, 1947

- Escapo amarelo-ferrugíneo ventralmente e no restante castanho-escuro ou preto.

Tégulas castanhas ou enegrecidas

9. Escapo amarelo-ferrugíneo ventralmente, na face dorsal castanho com mescla de ferrugíneo. Escutelo com nódoa basal preta, sem interromper a larga orla amarela (Fig. 6). PERU: Huánuco; Bolívia: La Paz, Beni; ARGENTINA: Salta; BRASIL: Acre . . . . . . . . . . quadrimaculatum (Cockerell, 1927)

- Escapo preto. Escutelo com a faixa apical amarela interrompida no meio, resultando duas nódoas laterais. MÉxıco: Tamaulipas . . . . . . . . . . . . . tamaulipanus Michener \& Ordway, 1964

10. Tegumento da cabeça quase inteiramente amarelo ou ferrugíneo, incluindo o clípeo

- Tegumento da cabeça quase inteiramente preto, clípeo preto ou com nódoas laterais amarelas

11. Tergos amarelos, com leve tonalidade acastanhada, faixa amarela larga do terceiro ao quinto tergo. Sexto tergo amarelo, com margem castanha ..... .

analuizae

- Tergos pretos, com faixa amarela estreita do terceiro ao quinto. Sexto tergo preto willineri

12. Sexto tergo amarelo com orla enegrecida $\ldots \ldots \ldots \ldots \ldots \ldots \ldots \ldots \ldots$

- Sexto tergo preto

13. Cabeça e mesosoma inteiramente pretos, ou com nódoas amarelas obsoletas. Antenas com escapo, pedicelo e flagelômero basal pretos ..... gualanense - Cabeça e mesosoma com desenhos amarelos; clípeo com nódoas laterais amarelas. Antenas com escapo, pedicelo e os dois flagelômeros basais amarelo-ferrugíneos. bettyae

14. Nódoas amarelas ou ferrugíneas interalveolares. Escapo, pedicelo e flagelômero

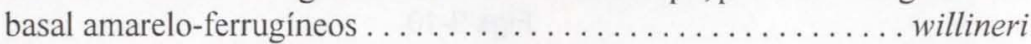

- Sem nódoas interalveolares amarelas ou ferrugíneas. Escapo preto, ou ao menos

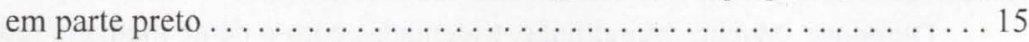

15. Clípeo preto ou com pequenas nódoas laterais amareladas. Tégulas pretas.

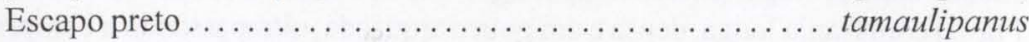
- Clípeo com duas grandes nódoas triangulares laterais amarelas. Tégulas castanhas ou amarelo-acastanhadas. Escapo em parte amarelo-ocráceo, restante preto quadrimaculatum 


\section{Notas sobre Bothranthidium}

MOURE (1947) descreveu Bothranthidium, um gênero peculiar de Anthidiinae com o mesoscuto mais longo que largo, tendo em mãos somente fêmeas. No ano seguinte MiCHENER (1948) considerou-o relacionado com Anthodioctes Holmberg, 1903, por ter em comum a carena pré-occipital completa. GRISWOLD \& MiCHENER (1988), nos comentários sobre Anthodioctes, concluíram que Bothranthidium poderia ser incluído em Anthodioctes, porém a decisão dependeria da descoberta do macho.

Comentários. Bothranthidium, Nananthidium e Anthodioctes Holmberg, 1903 têm em comum a carena pré-occipital unida à carena hipostomal e laminada ao longo da gena, menos nítida no vértice, e alvéolos em toda a área basal do propódeo.

Bothranthidium e Nananthidium têm o corpo alongado, com o mesoscuto mais longo que largo, depressão basal do escutelo quase tão larga como o diâmetro dos ocelos e, as fềmeas com três dentes mandibulares.

Nananthidium distingue-se pelos alvéolos basais do propódeo tão longos como o dobro da sua largura, tanto no meio como nos flancos e dispostos em declive, e pelo pterostigma, mais longo que o dobro do diâmetro dos ocelos; o macho tem o sexto tergo curto, seu comprimento aproximadamente um terço da largura, e o sétimo tergo também curto com dois pequenos dentes agudos laminados.

Bothranthidium tem os alvéolos basais do propódeo tão longos como largos no meio e um pouco mais alongados nos flancos, o pterostigma um pouco maior que o diâmetro dos ocelos; o macho tem o sexto tergo tão longo como a metade da sua largura, em vista dorsal, e o sétimo tergo projetado em dois largos lobos carenados.

Anthodioctes é caracterizado pelo mesoscuto mais largo que longo, o corpo sem o aspecto longilíneo, depressão basal do escutelo estreita, medindo quase a metade do diâmetro dos ocelos e o pterostigma quase tão longo como o dobro do diâmetro dos ocelos; o macho tem o sétimo tergo curto arredondado ou levemente bissinuado, sem lóbulos carenados ou dentes, pouco mais longo que o diâmetro dos ocelos; a fêmea tem quatro dentes mandibulares.

Tendo identificado, pela primeira vez, machos de Bothranthidium lauroi, única espécie conhecida do gênero, a seguir são dadas suas principais características, a fim de possibilitar comparações com outros gêneros.

\section{Bothranthidium lauroi Moure, 1947}

\section{Figs $9-10$}

Bothranthidium lauroi Moure, 1947, Publ. Avulsas Mus. Paranaense 3: 25.

Diagnose. Macho. Mandíbulas tridentadas com o dente mediano reduzido; antenas com os flagelômeros mais longos que seu diâmetro; tarsômeros anteriores (Fig. 9) com franja longa, densa e um pouco arqueada, ultrapassando o comprimento do basitarso, a franja mais curta nos tarsômeros distais; sexto e sétimo tergos voltados para baixo, o sexto tão longo como os anteriores, deprimido subapicalmente e com lâmina apical curta, sétimo tergo um pouco mais curto, com dois lobos 
carenados (Fig. 10), mais largos que o recorte mediano, com a pilosidade curta e voltada para o meio, achatados na face ventral; segundo e terceiro esternos com franja apical de pêlos finos, muito curta no meio; quarto e quinto esternos com o bordo glabro no meio, mais largamente no quinto; sexto esterno com carena mediana baixa terminando $\mathrm{em}$ tubérculo junto ao ápice.
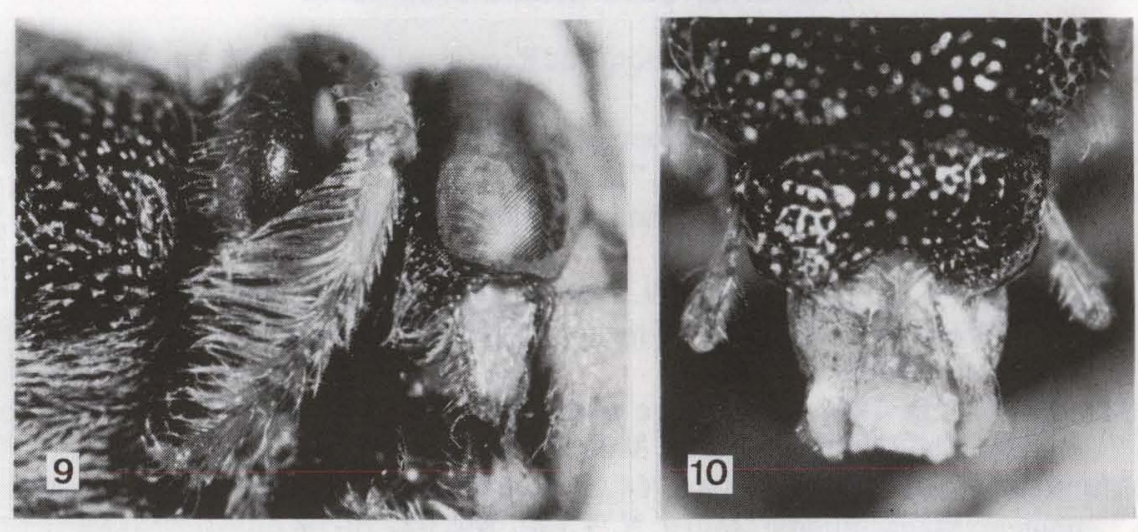

Figs 9-10. Bothranthidium lauroi, macho. (9) Cabeça, parte do mesosoma e da perna anterior; (10) tergos distais, parte dos gonóstilos e das valvas da genitália.

Tegumento preto, amarelo no clípeo e mandíbulas, os dentes mandibulares pretos; nódoa amarela na área supraclipeal, junto à sutura epistomal, projetada no meio em direção à fronte; paroculares inferiores amarelas, deixando pequena área preta junto aos alvéolos antenais e diminuindo bruscamente em direção aos olhos; estria pós-ocelar amarela, incluindo a carena pré-occipital e mais estreita atrás dos ocelos, alargando para os lados e contínua com as estrias genais amarelas que terminam a pouca distância da articulação mandibular; face ventral do escapo amarela. Mesosoma com as seguintes manchas amarelas: nódoa nos lobos pronotais; faixas látero-basais no mesoscuto, um pouco prolongadas discalmente; metade posterior do escutelo e das axilas; tégulas e pernas amarelo-acastanhadas, as pernas com amarelo na face externa das tíbias anteriores e de todos os basitarsos, os artículos basais das pernas enegrecidos. Tergo basal com nódoas laterais arredondadas amarelas; segundo tergo com pequenas faixas laterais também amarelas; terceiro ao quinto com faixa discal amarela estreita quase até o bordo lateral; sexto preto e o sétimo levemente acastanhado.

A fềmea tem o mesosoma e os tergos como no macho; com faixa subapical amarela no clípeo levemente trilobulada, às vezes com três pequenas manchas amarelas em vez de faixa contínua; estrias paroculares e pós-ocelar como no macho; pernas castanhas.

Distribuição geográfica. Bolivia, Santa Cruz; PARAgUAi: San Estanislao; Brasil, Espírito Santo, São Paulo, Paraná, Santa Catarina, Minas Gerais, Mato Grosso, Mato Grosso do Sul. 
AGRADECIMENTOS. Aos doutores Pe. Jesus S.Moure, pelo acesso às notas sobre os tipos de abelhas, Albino M. Sakakibara pelas fotos que ilustram este trabalho, Charles D. Michener do Snow Entomological Museum, University of Kansas e Jerome G. Rozen Jr., do American Museum of Natural History, pelo empréstimo de material para estudo.

\section{REFERÊNCIAS BIBLIOGRÁFICAS}

Cockerell, T.D.A. 1912. Descriptions and Records of Bees. XLIV. An. Mag. Nat. Hist. 9 (8): 554-568.

1927. Megachilid bees from Bolivia collected by the Mulford Expedition, 1921-22. Proc. U.S. Nat. Mus. 71: 1-22.

.1928. Bees collected by Nathan Banks in the vicinity of the Panama Canal. Psyche 35 (3): 173-181.

GRISWOLD, T.L. \& C.D. MiCHENER. 1988. Taxonomic observations on Anthidiini of the Western Hemisphere (Hymenoptera: Megachilidae). Jour. Kansas Ent. Soc. 61 (1): 22-45.

MiCHENER, C.D. 1948. The generic classification of the Anthidiine bees (Hymenoptera, Megachilidae). Amer. Mus. Novitates 1381: 1-29.

MicheNER, C.D. \& E. ORDWAY. 1964. Some Anthidiine bees from Mexico (Hymenoptera: Megachilidae). Journ. N. Y.Ent. Soc. 72: 70-78.

MoURE, J.S. 1947. Novos agrupamentos genéricos e algumas espécies novas de abelhas sulamericanas. Publ. Avulsas Mus. Paranaense, Curitiba, 3: 1-37.

UrBan, D. 1992. Considerações sobre Anthidulum Michener, stat.n. e Dicranthidium Moure \& Urban, stat.n. e descrições de espécies novas (Hymenoptera, Megachilidae). Revta bras. Zool. 9 (1/2): 11-28.

Recebido em 27.VI.1997; aceito em 23.VII.1998. 